\title{
Assessment of Diarrheal Disease Management Practice in Under-Five-Year Children According to WHO Guideline in Health Facilities of Hawassa City, SNNPR, Ethiopia
}

\author{
Usman Abdurehman Huluka ${ }^{1,2 *}$, Ahmed Hasan Dessiso ${ }^{3}$ (1) \\ ${ }^{1}$ College of Medicine, Hawassa University, Hawassa, Ethiopia \\ ${ }^{2}$ Faya General Hospital, Shashamane, Ethiopia \\ ${ }^{3}$ Departments of Statistics, College of Natural and Computational Science, Madda Walabu University, Bale Robe, Ethiopia \\ Email: *osmabdu97@gmail.com, ah30994@gmail.com
}

How to cite this paper: Huluka, U.A. and Dessiso, A.H. (2020) Assessment of Diarrheal Disease Management Practice in Under-Five-Year Children According to WHO Guideline in Health Facilities of Hawassa City, SNNPR, Ethiopia. Health, 12, 1345-1359. https://doi.org/10.4236/health.2020.1210096

Received: August 29, 2020

Accepted: October 12, 2020

Published: October 15, 2020

Copyright ( 2020 by author(s) and Scientific Research Publishing Inc. This work is licensed under the Creative Commons Attribution International License (CC BY 4.0).

http://creativecommons.org/licenses/by/4.0/

\section{Abstract}

Objective: To explore the practice of management of diarrhea in under-5-year children at health facilities found in Hawassa town, and associated factors with malpractice in comparison. Methodology: Cross Sectional study was conducted in 2 hospitals, 2 health centers and 2 private clinics that are found in Hawassa city which is found in Southern Nations, Nationalities and peoples (SNNP), $275 \mathrm{KM}$ to south from Addis Ababa, capital city of Ethiopia from august 2017-October 2017. Structured checklist was used to retrieve the required information from the patients on arrival and stay in pediatrics OPDs and wards. The data analysis carried out using SPSS version 20.0. Logistic regression was carried out to analyze the association between the independent and dependent variables. Statistically significant associations were declared at p-values of less than or equal to 0.05. Results: Out of 420, about 397 (94.5\%) children with diarrheal disease between the ages of 3 - 59 months were studied. The study subjects were from governmental hospitals (35.5\%), health centers $(34.5 \%)$ and private clinics $(30 \%)$ that are found in Hawassa City. Sign of dehydration was $66(17 \%)$ of which majority 59 (83\%) of them were rehydrated. As to Zink supplementation, only 180 (45\%) received it; antibiotics were the commonly (59.1\%) prescribed drugs. Only $43.3 \%$ of children were appropriately managed. Hospitals had higher odds of inappropriate management of diarrhea with AOR $=1.61$ (95\% CI: $1.04-2.5)$ and children one year or younger were more inappropriately managed for diarrhea at the health facilities with AOR of 2.3 (95\% CI: 1.57 - 4.41). Conclusions: In the current study the management of diarrhea at the health facilities is unsatis- 
factory as only less than half of children with diarrhea were properly managed. Treatment of diarrhea at hospital level and the patient's age being less than 1 year were found to significantly affect the level of mismanagement of the diarrheal disease. Therefore, orientation and trainings for health care providers especially GPs and Residents should be given to adhere to recommended zinc therapy, Oral Rehydration Salts (ORS) replacement therapy and rational antibiotics prescription.

\section{Keywords}

Antimicrobial, Diarrhea Management, Malpractice, ORS, Under-Five Children, Zink Supplementation

\section{Introduction}

Diarrhea is defined as passage of 3 or more unusually loose stool or watery stool of any frequency within $24 \mathrm{hrs}$ [1]. Diarrheal disease remains second cause of death in under-5-year children globally [2]. According to WHO report each year there are about 2 billion cases of diarrheal disease in under-5-year children of which 1.9 million die [3]. In Africa, 800,000 children die each year from diarrhea and dehydration which account for $25 \%$ to $75 \%$ of all childhood diseases [ 4 ].

Ethiopia has one of the highest under-five mortality rates with more than 321,000 children under the age of five dying every year and $20 \%$ of the deaths are attributed to diarrheal diseases [5]. Furthermore, according to Ethiopia Demographic Health Survey (DHS) 2016, 12\% of children younger than 5 years of age had diarrhea in the preceding two weeks and the figure was as high as $23 \%$ amongst children 6 - 11 months of age [6]. More than three-quarters of all diarrheal deaths could be prevented with full coverage and utilization of ORS and adjunct zinc supplementation [7]. There is evidence that ORS may reduce diarrhea specific mortality by as high as $93 \%$ [8]. In sub-Saharan Africa, only about one in three children experiencing diarrheal episodes receive ORS, and the proportion receiving zinc is below 5\% [9]. Coverage of ORS from 2005-2014 in Ethiopia was $26 \%$ and the coverage of zinc during the same period was amazingly nil (0\%) [10].

According to WHO Guidelines, children that will be benefited from antibiotics are only those with bloody diarrhea (probable shigellosis), suspected cholera with severe dehydration, and serious associated non-intestinal infections such as pneumonia [1]. "Antidiarrheal” and anti-emetics drugs didn't show benefits for children with acute or persistent diarrhea and some may even end with fatal side effects [1].

Appropriate management of children with diarrheal disease requires basic knowledge \& essential clinical evaluation skills for identifying possible etiology, hydration status, identifying predisposing factors and doing necessary investigations [11]. Although mismanagement and malpractice of families during man- 
agement of children with diarrheal disease at home, like preventing from fluid intake including feeding, may contribute much for the deaths [12], it is difficult to argue that the management of children who sake medical care is optimal.

Antimicrobial resistance is dramatically increasing worldwide in response to antibiotic use but much of it is due to inappropriate over uses and causing significant morbidity and mortality [13]. Irrational use of drugs does not benefit children with diarrheal disease and may even harm by resulting in unwanted adverse effects and resistance of antimicrobials [13]. In addition to this, it will impose unnecessary costs for the family as well as for the country [13].

The use of treatment guidelines based on clinical presentation is common in developing countries due to unavailability of laboratory services and patient overload [14]. In Ethiopia guidelines used are, Ethiopian Medicines Formulary, National Standard Treatment Guidelines together with WHO guidelines for the management of common illnesses with limited resources (INMCI) [5] [15].

One aspect of reducing children mortality from diarrheal disease should focus on optimizing the care. In order to do that it will be important to know what is being really practiced at all level of health institutions. To the level of authors knowledge, only few studies is there which focus on assessing diarrheal disease management in Ethiopia especially at hospitals and private clinic level. As malpractice in diarrheal disease management is found to be high, it will be very important to study how current practice looks like and identify factors contributing to the mismanagement; thereby addressing the gap and taking necessary measures. Hence, the current study was aimed to explore the practice of management of diarrhea disease in under-five-year children and associated factors at health facilities in Hawassa town, Ethiopia. The findings from this study has shown what efforts look like in decreasing morbidity \& mortality from diarrheal disease and it will serve as baseline for further studies on identifying where the gap is and taking necessary intervention to reduce children dying from diarrheal disease.

\section{Methodology}

\subsection{Study Design and Study Population}

A health facility based cross sectional study was conducted in 2 hospitals (one of which is teaching referral hospital), 2 health centers and 2 private clinics that are found in Hawassa city from August 2017 to October 2017. The target population of our study was Children under five years of age with diarrheal disease who visit the randomly selected health centers, private clinics and hospitals during study period.

\section{Inclusion criteria:}

- Children from age between 2 months and 5 years with diarrhea.

- Children who visited health centers in the study period.

- Child's mother/caregiver present and able to give response. 
- Participants who signed informed consent.

\section{Exclusion criteria:}

- Children who were already on treatments before they visit the health institution.

- Infants younger than two months of age and older than five years of age.

- Children who developed diarrhea while they were in the hospital.

- Children who have diarrheal lasting more 14 days.

- Participants who refuse to participate in the study and those with incomplete patient data were excluded.

\subsection{The Sample Size Determination}

The sample size was calculated by using formula

$$
n=\left[Z_{1-\alpha / 2}\right]^{2} p(1-p) / D^{2}
$$

where: $n=$ the minimum sample size required.

$p=$ prevalence of inappropriate practice of diarrheal disease management from study conducted in health centers of Addis Ababa [16].

$D=$ the margin of tolerance.

$Z=$ the standard normal variation at confidence level.

The minimum sample size required was obtained by taking a prevalence rate of $54 \%(0.54)$ and confidence interval of $95 \%$ and the margins of error is $5 \%$ (0.5).

The sample was calculated as

$$
n=[1.96]^{2} 0.54(1-0.54) /(0.5) 2=382
$$

$10 \%$ of the sample size was added for contingency and it became 420 -sample size.

\subsection{Sampling Procedure}

Preliminary data on patient load of the hospitals, private clinics and health centers for under-5-year children who were diagnosed to have diarrheal disease was collected. Number of institutions that were required for data collection in order to get the calculated sample size in above mentioned study period was estimated. Among the hospitals, pediatric patient flow was found to be very minimal in the 4 private hospitals and the 2 governmental hospitals were selected without using any sampling method. 2 Health centers were selected using simple lottery method. Among 3 private pediatrics clinics, 2 were selected using simple lottery sampling methods. Data collection process continued during the study period till above stated quota was filled.

\subsection{Study Variables}

Dependent variable: practice of diarrheal disease management.

Independent variables are categorized as follows:

Demographic variable: age, sex, Vitamin A supplementation and vaccination 
status.

Disease related variable: duration of the current episode of diarrhea, stool characteristics, frequency of stools/24hrs, dehydration status, Vomiting, fever, cough or shortness of breath, malnutrition.

Management related variables: rehydration fluid (IV or ORT), zinc supplementation, ORS, antiemetic, antibiotics, stool microscopy order, WBC order, level of health institution, category of health professional.

\subsection{Data Collection Technique and Management}

The structured and pretested checklist was developed after reviewing relevant literature to include all the possible variables that address the objectives of the study. The data collectors had selected eligible children during triage by asking their complaints and then took consent if the caregivers are willing to participate in the study. The data collectors filled some of the data like socio-demography and complaints of patient initially. The other components of the questioners like investigations and medications given to the child were filled after they finished their stay either from the card or checking medications from prescription paper. The treating health personnel were blinded about the ongoing study in order to avoid bias.

\subsection{Data Processing and Analysis}

SPSS version 20 software package was used for data entry as well as analysis. Descriptive statistics like frequencies and percentages were used to summarize the socio-demographic characteristics of the study participants calculated to describe findings while binary logistic regression was used for looking association in variables. Those variables showing $p$ value $<0.25$ with outcome variables in the bivariate analysis and deemed to be important from previous study were selected as candidate variables for multivariable logistic regression analysis. Before further analyses were carried out using multivariable analysis, multicollinearity was checked among selected independent variables using the variance inflation factor and none was found. Additionally, Goodness of fit of the final model was checked by Hosmer and Lemeshow and was found fit. $p$ value less than 0.05 was taken as statistically significant.

\subsection{Data Quality Control}

From every selected study center one nurse was selected and all the selected nurses were given one day intensive training on the aim of the study, data collection tools and informed consent process. They were also trained on how to assess for malnutrition and dehydration. To ensure data quality, pretest of data collection was done in 40 patients (5\%) that were not included in the data for the final study. Trained nurses under the supervision of the investigator have done the data collection. The treating health personnel were not informed about the ongoing study in order to avoid bias. 


\subsection{Ethical Consideration}

Ethical clearance was obtained from Hawassa University, College of Medicine and Health Science Institutional Review Board. The permission to conduct the study was obtained from the regional health office and administrators of respective health institutions. The information from the patient was kept confidential, only the data collector had the access to information, which talks about the patient information other than the topic of interest. The study participants were not harmed by any means for their involvement in the study.

\section{Results and Discussion}

\subsection{Demography of Study Participants}

Among the total 420 selected participants, 397 mothers/caretakers having children between the ages of 3 - 59 months were studied giving a response rate of $94.5 \%$. The study subjects were from governmental hospitals (35.5\%), health centers $(34.5 \%)$ and private clinics $(30 \%)$ that are found in Hawassa City. About 23 cases were excluded due to unwilling to participate in the study. Among the children 239 (60.2\%) were males, and 158 (40\%) of participants are below 1 year of age and the rest are between 1 years and 5 years of age. It was the initial visit of health facilities after the onset of diarrhea for 228 (57.4\%) of the children, while the rest 169 (42.6\%) had previousvisits (Table 1).

\subsection{Characteristics of Diarrhea in Children 3 - 59 Months}

The duration, type, frequency and management of diarrhea in under-5-year children assessed and presented in Table 2. Accordingly, most of 357 (90\%) of the children presented to the health facilities within the 72 hours of diarrhea, and the diarrhea was mostly $(240,60.5 \%)$ watery in type, and up $3-4$ times in frequency per day in 297 (75\%) of the cases. In addition, vomiting was complained by nearly half, 185 (46.6\%) of the children with diarrhea, and cough or shortness of breath was complained by one fifth of the study participants (Table 2).

Figure 1 shows immunization status of studied children and found that majority $372(93.7 \%)$ were either completed or up-to-date vaccinated. The defaulters and unvaccinated children were $3.8 \%$ and $1.3 \%$ respectively for unknown reasons.

\subsection{Management Practices of Diarrhea in Children by Health Professionals}

Among 397 children that had visited the health facilities stool microscopy was done for 344 (86.6\%) of them, though 240 (60.5\%) of them were just having watery diarrhea. WBC was ordered for $64(16.1 \%)$ of the study participants. Of all study subjects signs of dehydration was observed in 66 (17\%) of cases of which majority 59 (83\%) of them were rehydrated. As to Zink supplementation, only 180 (45\%) children were received it. Among health professionals, zinc prescription 
Table 1. Demographic, vaccination, vitamin A and previous visits of children with diarrhea.

\begin{tabular}{|c|c|c|c|}
\hline Variables & Categories & Number & Percent \\
\hline \multirow{2}{*}{ Residence } & Urban & 236 & 59.4 \\
\hline & Rural & 161 & 40.6 \\
\hline \multirow{3}{*}{$\begin{array}{l}\text { Marital status of the } \\
\text { mother/caretaker }\end{array}$} & Married & 332 & 83.6 \\
\hline & other & 65 & 16.4 \\
\hline & $3-6$ month & 52 & 13.1 \\
\hline \multirow{3}{*}{ Child age } & 7 - 12 month & 106 & 26.7 \\
\hline & $13-24$ month & 122 & 30.7 \\
\hline & 25 - 60 month & 117 & 29.5 \\
\hline \multirow{2}{*}{ Child sex } & Male & 239 & 60.2 \\
\hline & Female & 158 & 39.8 \\
\hline \multirow{4}{*}{$\begin{array}{c}\text { Vitamin A } \\
\text { supplementation }\end{array}$} & Yes & 205 & 51.6 \\
\hline & No & 95 & 23.9 \\
\hline & Unknown & 45 & 11.3 \\
\hline & Age inappropriate & 52 & 13.1 \\
\hline \multirow{2}{*}{ History of previous visit } & Yes & 169 & 42.6 \\
\hline & No & 228 & 57.4 \\
\hline \multirow{2}{*}{ Signs of malnutrition } & Yes & 36 & 9.1 \\
\hline & No & 361 & 90.9 \\
\hline \multirow{4}{*}{$\begin{array}{l}\text { Level of health } \\
\text { institution }\end{array}$} & Health center & 137 & 34.5 \\
\hline & Private clinic & 119 & 30.0 \\
\hline & District hospital & 101 & 25.4 \\
\hline & Teaching hospital & 40 & 10.1 \\
\hline \multirow{5}{*}{$\begin{array}{l}\text { Status of health } \\
\text { professionals }\end{array}$} & Nurses & 57 & 14.4 \\
\hline & Health officers & 83 & 20.9 \\
\hline & Pediatric residents & 41 & 10.3 \\
\hline & GPs & 101 & 25.4 \\
\hline & Pediatricians & 114 & 28.7 \\
\hline
\end{tabular}

rate was $28 \%$ and $16 \%$ by nurses and General practitioners respectively while it was $87 \%$ by pediatricians. Additional medications were prescribed for higher proportions 287 (72\%) of children. 178 (59.1\%) participants are given antibiotics alone $(44.8 \%)$ or in combination with either antiemetic (2.7) or antipyretics (11.6). Among 234 children that were given Antibiotics, misuse of Antibiotics was found to be $27.4 \%$. Regarding advises on ORS supplementation, almost all (96\%) of mothers were advised to provide ORS per loss to their children (Table 3). 
Table 2. Characteristics of diarrhea, clinical and laboratory finding of the children.

\begin{tabular}{|c|c|c|c|}
\hline Variables & $\begin{array}{c}\text { Inappropriate diarrhea } \\
\text { Management } n(\%)\end{array}$ & $\begin{array}{c}\text { Appropriate diarrhea } \\
\text { management } n(\%)\end{array}$ & $\begin{array}{c}\text { COR } \\
(95 \% \mathrm{CI})\end{array}$ \\
\hline \multirow{3}{*}{ Duration of diarrhea } & $<72 \mathrm{hrs}$ & 357 & 89.9 \\
\hline & 72 hrs - 7 days & 37 & 9.3 \\
\hline & 8 to 14 days & 3 & 0.8 \\
\hline \multirow{4}{*}{ Type of diarrhea } & Watery & 240 & 60.5 \\
\hline & Bloody & 35 & 8.8 \\
\hline & Mucoid & 60 & 15.1 \\
\hline & loose stool & 60.2 & 15.6 \\
\hline \multirow{3}{*}{ Frequency of diarrhea } & 1 to 2 & 93 & 23.4 \\
\hline & 3 to 5 & 297 & 74.8 \\
\hline & 6 to 8 & 7 & 1.8 \\
\hline \multirow{5}{*}{$\begin{array}{l}\text { Stool microscopy } \\
\text { finding }\end{array}$} & Puss cells & 93 & 27.1 \\
\hline & RBCs & 28 & 8.1 \\
\hline & Bacteria & 81 & 23.6 \\
\hline & Parasite & 30 & 8.7 \\
\hline & Normal & 113 & 32.9 \\
\hline \multirow{2}{*}{ Child had vomiting } & Yes & 185 & 46.6 \\
\hline & No & 212 & 53.4 \\
\hline \multirow{2}{*}{$\begin{array}{l}\text { Child had cough or } \\
\text { shortness of breath }\end{array}$} & Yes & 77 & 19.4 \\
\hline & No & 320 & 80.6 \\
\hline
\end{tabular}

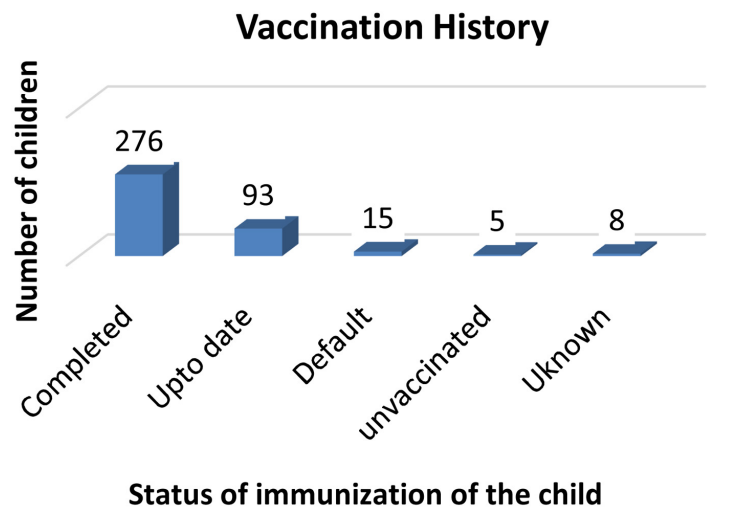

Figure 1. Immunization status of children with diarrhea at health facilities of Hawassa city, SNNPR, 2017.

As per WHO diarrhea management guidelines the appropriate diarrhea management practices was 172 (43.3\%) while, more than half, 225 (56.7\%) were inappropriately managed at the health facilities.

\subsection{The Factors Associated with Management Practices of Diarrhea in Under-Five-Year Children}

Table 4 presented Bivariate analyses of factors associated with inappropriate management practices of diarrhea in children aged 3 - 59 months at the health facilities in Hawassa city. Variables entered in to the model were child age and 
Table 3. Management of children with diarrhea at health facilities of Hawassa city, SNNPR, 2017.

\begin{tabular}{|c|c|c|c|}
\hline Variables & Categories & Number & Percent \\
\hline \multirow{2}{*}{$\begin{array}{l}\text { Signs of dehydration } \\
\qquad(n=397)\end{array}$} & Yes & 66 & 16.6 \\
\hline & No & 331 & 83.4 \\
\hline \multirow{2}{*}{$\begin{array}{l}\text { Rehydration done for those } \\
\qquad(n=66)\end{array}$} & Yes & 59 & 83 \\
\hline & No & 7 & 17 \\
\hline \multirow{2}{*}{$\begin{array}{l}\text { Advised to give ORS per } \\
\text { loss }(n=397)\end{array}$} & Yes & 381 & 96.0 \\
\hline & No & 16 & 4.0 \\
\hline \multirow{2}{*}{$\begin{array}{l}\text { Zink supplementation } \\
\text { done }(n=397)\end{array}$} & Yes & 180 & 45.3 \\
\hline & No & 217 & 54.7 \\
\hline \multirow{6}{*}{$\begin{array}{l}\text { Additional medication } \\
\quad \text { given }(n=397)\end{array}$} & Yes & 287 & 72.3 \\
\hline & No & 110 & 27.7 \\
\hline & Antibiotics alone & 178 & 44.8 \\
\hline & antipyretics \& antibiotics & 45 & 11.6 \\
\hline & Metronidazole & 22 & 5.8 \\
\hline & Antipyretics & 12 & 3 \\
\hline \multirow{5}{*}{$\begin{array}{c}\text { Types of additional } \\
\text { medication prescribed }\end{array}$} & antibiotics \& anti emetics & 11 & 2.7 \\
\hline & anti-helmenths & 8 & 2 \\
\hline & Antimalarial & 7 & 1.8 \\
\hline & Antiemetic & 3 & 0.7 \\
\hline & Other & 1 & 0.2 \\
\hline \multirow{2}{*}{ Stool microscopy done } & Yes & 344 & 86.6 \\
\hline & No & 53 & 13.4 \\
\hline \multirow{2}{*}{ WBC count done } & Yes & 64 & 16.1 \\
\hline & No & 335 & 83.9 \\
\hline
\end{tabular}

sex, history of revisit, duration and frequency of diarrhea, healthcare providers' profession and types of health institutions. Accordingly, male sex, younger age, GPs and residents and hospitals were found to associate with inappropriate management practices of diarrhea at the facilities while, the rest variables were not associated with diarrhea management malpractices.

This Multivariable analyses was done to control for potential confounders that might be associated with inappropriate management practices of diarrhea by health professionals among 3 - 59 months aged children treated at health facilities. And, variables having $p$ value $\leq 0.2$ in bivariate analyses were re-entered in to the model. These are child age and sex, history of revisit, duration of diarrhea, category of the managing health professional and types of health institutions. Accordingly, after multivariable analyses only child age and health institution type were found to be statistically associated with malpractices of diarrhea in $<5$ years children, while the rest variables lost association after the model.

Age of children with diarrhea was found to be associated with diarrhea management malpractices in that those children $\leq 1$ year were about one and half 
Table 4. Bivariate analyses of factors associated with inappropriate management practices of diarrhea for 3 - 59 months old children, Hawassa city health facilities, SNNPR, 2017.

\begin{tabular}{|c|c|c|c|c|}
\hline Variables & $\begin{array}{c}\text { Inappropriate } \\
\text { diarrhea } \\
\text { management } \\
\text { No (\%) }\end{array}$ & $\begin{array}{c}\text { Appropriate } \\
\text { diarrhea } \\
\text { management } \\
\text { No (\%) }\end{array}$ & COR $(95 \% \mathrm{CI})$ & $p$ Value \\
\hline \multicolumn{5}{|l|}{ Child sex } \\
\hline Male & $145(64.4)$ & $94(54.7)$ & $1.5(1.00-2.26)$ & 0.04 \\
\hline Female & $80(35.6)$ & $78(45.3)$ & 1 & \\
\hline \multicolumn{5}{|l|}{ Child Age } \\
\hline$\leq 1$ year & $100(44.4)$ & $58(33.7)$ & $1.6(1.04-2.37)$ & 0.03 \\
\hline$>1$ year & $125(55.6)$ & $114(66.3)$ & 1 & \\
\hline \multicolumn{5}{|l|}{ History of Revisit } \\
\hline Yes & $99(44)$ & $70(40.7)$ & $1.14(0.77-1.71)$ & 0.51 \\
\hline No & $126(56)$ & $102(59.3)$ & 1 & \\
\hline \multicolumn{5}{|l|}{ Duration of diarrhea } \\
\hline$\leq 72$ hours & $197(87.6)$ & $160(93)$ & 1 & \\
\hline$>72$ hours & $28(12.4)$ & $12(7)$ & $0.53(0.26-1.07)$ & 0.07 \\
\hline \multicolumn{5}{|l|}{ Frequency of diarrhea } \\
\hline$<$ three times a day & $219(97.3)$ & $171(99.4)$ & 1 & \\
\hline$\geq$ three times a day & $6(2.7)$ & $1(0.6)$ & $0.21(0.03-1.8)$ & 0.12 \\
\hline \multicolumn{5}{|c|}{ Types of health professionals } \\
\hline Nurse & $33(14.7)$ & $24(14)$ & $1.84(0.98-3.46)$ & 0.06 \\
\hline $\mathrm{HO}$ & $42(18.7)$ & $41(24)$ & $1.43(0.81-2.6)$ & 0.21 \\
\hline GPs and residents & $99(44)$ & $35(20.5)$ & $3.94(2.32-6.67)$ & $<0.001$ \\
\hline Pediatricians & $51(22.7)$ & $71(41.5)$ & 1 & \\
\hline \multicolumn{5}{|l|}{ Types of health institutions } \\
\hline Health centers & $72(32)$ & $65(37.8)$ & 1 & \\
\hline Private clinics & $47(20.9)$ & $72(41.9)$ & $0.59(0.36-0.97)$ & 0.04 \\
\hline Governmental hospitals & $106(47.1)$ & $35(20.3)$ & $2.73(1.64-4.54)$ & $<0.001$ \\
\hline
\end{tabular}

times more likely to be inappropriately managed compared with children aged above one year, $\mathrm{AOR}=1.61$ (95\% CI: $1.04-2.50)$. Another variable showing association was type of health institution providing the health care services. Hence, the odd of malpractices at the government hospitals was 2 times higher compared to government health centers with AOR of 2.3 (95\% CI: 1.57 - 4.41) (Table $5)$.

\section{Discussion}

A study conducted on 397 children with diarrhea at health facilities in Hawassa City aimed at assessing the patterns of diarrhea management, appropriate practices by health professionals and associated factors. Most of dehydrated children were rehydrated 59/66, only $45 \%$ were supplemented with Zink, and similarly, 
Table 5. Multivariable analyses of factors associated with inappropriate management practices of diarrhea for 3 - 59 months old children, Hawassa City Health Facilities, SNNPR, 2017.

\begin{tabular}{|c|c|c|c|c|}
\hline \multirow[t]{2}{*}{ Variables } & $\begin{array}{c}\text { Inappropriate } \\
\text { diarrhea } \\
\text { management }\end{array}$ & $\begin{array}{c}\text { Appropriate } \\
\text { diarrhea } \\
\text { management }\end{array}$ & COR $(95 \% \mathrm{CI})$ & $\operatorname{AOR}(95 \% \mathrm{CI})$ \\
\hline & No (\%) & No (\%) & & \\
\hline \multicolumn{5}{|l|}{ Child sex } \\
\hline Male & $145(64.4)$ & $94(54.7)$ & $1.5(1.00-2.26)$ & $1.49(0.97-2.30)$ \\
\hline Female & $80(35.6)$ & $78(45.3)$ & 1 & \\
\hline \multicolumn{5}{|l|}{ Child Age } \\
\hline$\leq 1$ year & $100(44.4)$ & $58(33.7)$ & $1.6(1.04-2.37)$ & $1.61(1.04-2.50)$ \\
\hline$>1$ year & $125(55.6)$ & $114(66.3)$ & 1 & 1 \\
\hline \multicolumn{5}{|l|}{ History of revisit } \\
\hline Yes & $99(44)$ & $70(40.7)$ & $1.14(0.77-1.71)$ & 0.51 \\
\hline No & $126(56)$ & $102(59.3)$ & 1 & \\
\hline \multicolumn{5}{|c|}{ Duration of diarrhea } \\
\hline$\leq 72$ hours & $197(87.6)$ & $160(93)$ & 1 & 1 \\
\hline$>72$ hours & $28(12.4)$ & $12(7)$ & $0.53(0.26-1.07)$ & $1.84(0.88-3.86)$ \\
\hline \multicolumn{5}{|c|}{ Types of health institution } \\
\hline Health centers & $72(32)$ & $65(37.8)$ & 1 & 1 \\
\hline Private clinics & $47(20.9)$ & $72(41.9)$ & $0.59(0.36-0.97)$ & $0.60(0.36-1.00)$ \\
\hline $\begin{array}{c}\text { Governmental } \\
\text { hospitals }\end{array}$ & $106(47.1)$ & $35(20.3)$ & $2.73(1.64-4.54)$ & $2.31(1.57-4.41)$ \\
\hline
\end{tabular}

$59.1 \%$ of the children received antibiotics. The appropriate management practices of diarrhea among 2 - 59 months children was $43.3 \%$.

In this study, $19 \%$ of children were diagnosed to have dehydration and majorities $(83 \%)$ of them were rehydrated as per the recommendation. This is in line with the recommendations of FMOH guideline stating that the presence of dehydration, blood in the stool and duration of diarrhea should be assessed properly before initiating treatment, for it guides healthcare providers on the appropriate medications and other therapeutic interventions [5]. And also, the target of treating diarrheal disease should be to prevent and treat dehydration [17].

This study identified zinc supplementation to children with diarrhea as only $180(45.3 \%)$. This result is comparative to the finding from study done at Addis Ababa Health centers (43.8\%) and much higher than report of study from health centers of Iraq and Tanzania which were $1.25 \%$ and $28 \%$ respectively [14] [18]. However, this finding is in contrary to the WHO recommendations in the management of acute diarrhea to include zinc usage in combination with the supplementation of ORS [19]. This zinc supplementation found essential as the WHO and UNICEF brought attention to the impact of zinc in reducing the severity of the diarrheal episode and the number of subsequent acute diarrheal 
disease episodes in children younger than 5 years.

As to the antibiotics prescription rate, this study distinguished about 234 (59.1\%) of children to have received antibiotics. These findings are even higher than WHO estimate that more than $40 \%$ of the children with acute diarrhea in developing countries received antibiotics [20]. However, this result is not as significant as similar study conducted in Tanzania and Addis Ababa which shown $80 \%$ and $73 \%$ of children with acute diarrhea were given antibiotics respectively [14] [16]. These differences might be related to the study setting differences that this study included private and government institutions like hospitals while the latter were exclusively done at the public health centers. Unlike Indian study, which was conducted in New Delhi, which showed significant difference in antibiotics prescribing patterns between public and private institutions $43 \%$ and $69 \%$ respectively, there was no substantial difference (58.2\% vs $61.3 \%$ ) [21]. The current findings is supported by a body of science stating overprescribing, misuse of drugs including antibiotics as the most common problems of irrational drug use by prescribers as well as consumers [22].

Moreover, the findings of this study shows almost all (96\%) of mothers were advised to provide ORS per loss to their children with diarrhea. This is in line with recommendation by WHO stating, unless the patient is comatose or severely dehydrated, ORS solution therapy is accepted as the gold standard to achieve clinically efficacious and cost-effective management of dehydration and its complication [23]. This finding shows much better practice with regard to ORS prescription when it is paralleled to WHO estimates which showed among children with acute diarrhea in developing Countries, less than $60 \%$ of them received ORS [20]. And, also consistent with other similar study done in Kenya reported ORS prescription rate by healthcare workers to be as high as 90\% [19].

On the other hand, the finding of the current study is little bit higher to study conducted in Indian Hospitals reported $82 \%$ of children with diarrhea received ORS [24]. And much higher to study conducted in Addis Ababa Health centers which revealed $49.4 \%$ of children with diarrhea received ORS [16].

Malpractices like Antiemetic and Antidiarrheal agents' prescription were 3.4\% and $0 \%$. This is much lower than study done in Baghdad which showed 33.2\% and $12.8 \%$ prescription of Antiemetic and Antidiarrheal agents respectively [18]. It is closer to finding of study from Addis Ababa health center showing only 7\% of children were given Antiemetic with null Antidiarrheal prescription [16]. Stool microscopy was done for $344(86.6 \%)$ of children who visited the health facilities with diarrheal complaint which is significantly higher than the study done at health centers of Addis Ababa which shown to be 37.4\% [16]. When the necessity of stool microscopy was analyzed based on the type of diarrhea the rate of malpractice was found to be $56.3 \%$. WBC count was done for $64(16.1 \%)$ of children and $26.4 \%$ of the order were not rational.

Appropriate diarrhea management practices was 172 (43.3\%) in the current study while, more than half, 225 (56.7\%) were inappropriately managed. Similar to the current study, in Tanzania about $54 \%$ of watery diarrhea was managed 
inappropriately by healthcare providers [14]. Age of children with diarrhea was found to be statistically associated with inappropriate management practices of diarrhea in which those children $\leq 1$ year were about one and half times more likely to be inappropriately managed compared with children aged above one year. This findings are similar to study conducted in Addis Ababa reporting appropriate management of diarrhea for children with 2 - 11 months were $54 \%$ less compared to older children [16].

However, this association is in contrast with the study done in Tanzania where inappropriate antibiotic prescription was significantly associated with prescriber being a clinical officer and assistant medical officer instead of age and levels of health institutions providing diarrhea treatment [14]. Another variable showing strong association with inappropriate diarrhea management practices was health facilities where hospitals odd of malpractices was about three times higher compared to health centers. This indicates diarrhea management practices were unsatisfactory in Government Hospitals where children are mainly managed by General practitioners and Residents. This could be due to poor adherence to guidelines like IMNCI.

\section{Conclusions and Recommendations}

This study assessed patterns and appropriateness of diarrhea management practice among $<5$ years children in health facilities at Hawassa City. The health professionals especially general practitioners and residents were not sticking to the guidelines regarding laboratory investigations, the use of zinc supplementation and antimicrobials prescription in management of diarrhea. Hence, majority of the children diagnosed with signs of dehydrations were rehydrated, while only $45 \%$ of the children with diarrhea supplemented with zinc. The pattern of antibiotics prescription shows more than half of the children received it to treat diarrhea. There is over investigating children with diarrheal disease. Diarrhea was inappropriately managed in more than half of the cases, and as a factor hospitals had higher odds of inappropriate management of diarrhea, and children one year or younger were more inappropriately managed for diarrhea at the health facilities.

From the findings of this study, it is recommended that:

- Zinc prescription should be scaled up for the management of diarrhea in all the health facilities of Hawassa City.

- The health professional at the government Hospitals should stick to the recommended WHO or IMNCI guidelines in the management of diarrhea.

- Emphases should be given to the management of diarrhea in younger children aged 1 year or lower.

- Further studies should be done to identify whether this malpractice is knowledge or attitude gap and then should be acted accordingly.

\section{Conflicts of Interest}

The authors declare no conflicts of interest regarding the publication of this paper. 


\section{References}

[1] World Health Organization (2005) The Treatment of Diarrhea-A Manual for Physician and Senior Health Workers. 4th Rev. Edition, WHO, Geneva.

[2] Pond, K., Rueedi, J. and Pedley, S. (2004) Pathogens in Drinking Water Sources. Robens Centre for Public and Environmental Health, University of Surrey, Guildford.

[3] Farthing, M., Salam, M.A., Lindberg, G., Dite, P., Khalif, I., Salazar-Lindo, E., Ramakrishna, B.S., Goh, K.L., Thomson, A., Khan, A.G. and Krabshuis, J. (2013) Acute Diarrhea in Adults and Children: A Global Perspective. Journal of Clinical Gastroenterology, 47, 12-20. https://doi.org/10.1097/MCG.0b013e31826df662

[4] Hamer, D.H., Simon, J., Thea, D., Keusch, G.T., Hernandez-Avila, M. and Lazcano-Ponce, E. (1998) Childhood Diarrhea in Sub-Saharan Africa. Child Health Research Project Special Report, Vol. 2, 32.

[5] Fmoh, W. (2012) Integrated Management of Newborn and Childhood Illness, Part 2. Module, 2.

[6] CSA-Ethiopia IC International (2012) Ethiopia Demographic and Health Survey 2011. Central Statistical Agency of Ethiopia and ICF International, Addis Ababa and Calverton.

[7] Jones, G., Steketee, R.W., Black, R.E., Bhutta, Z.A., Morris, S.S. and Bellagio Child Survival Study Group (2003) How Many Child Deaths Can We Prevent This Year? The Lancet, 362, 65-71. https://doi.org/10.1016/S0140-6736(03)13811-1

[8] Munos, M.K., Walker, C.L. and Black, R.E. (2010) The Effect of Oral Rehydration Solution and Recommended Home Fluids on Diarrhoea Mortality. International Journal of Epidemiology, 39, i75-i87. https://doi.org/10.1093/ije/dyq025

[9] UNICEF (2015) Global Databases Based on Multiple Indicators Cluster Surveys, Demographic and Health Surveys and Other Nationally Representative Sources. New York.

[10] International Vaccine Access Center (IVAC) at Johns Hopkins Bloomberg School of Public Health. Pneumonia and Diarrhea Progress Report 2013.

https://www.jhsph.edu/ivac/wp-content/uploads/2018/04/IVAC-2014-PneumoniaDiarrhea-Progress-Report.pdf

[11] Cooke, M.L. (2010) Causes and Management of Diarrhoea in Children in a Clinical Setting. South African Journal of Clinical Nutrition, 23, S42-S46. https://doi.org/10.1080/16070658.2010.11734269

[12] Carter, E., Bryce, J., Perin, J. and Newby, H. (2015) Harmful Practices in the Management of Childhood Diarrhea in Low- and Middle-Income Countries: A Systematic Review. BMC Public Health, 15, 788. https://doi.org/10.1186/s12889-015-2127-1

[13] Holloway, K. and Van Dijk, L. (2011) The World Medicines Situation 2011. Rational Use of Medicines. WHO, Geneva.

[14] Gwimile, J.J., Shekalaghe, S.A., Kapanda, G.N. and Kisanga, E.R. (2012) Antibiotic Prescribing Practice in Management of Cough and/or Diarrhoea in Moshi Municipality, Northern Tanzania: Cross-Sectional Descriptive Study. Pan African Medical Journal, 12, 103.

[15] DACA (2010) Standard Treatment Guideline for Health Centers: Drug Administration and Control Authority of Ethiopia. 1-349.

[16] Gashaw, A. (2015) Assessment of the Management of Diarrhea in Children under Five in Health Centers of Addis Ababa City Administration, Ethiopia. Doctoral 
Dissertation, Addis Ababa University, Addis Ababa.

[17] Ismaeel, A.Y., Al Khaja, K.A., Damanhori, A.H., Sequeira, R.P. and Botta, G.A. (2007) Management of Acute Diarrhoea in Primary Care in Bahrain: Self-Reported Practices of Doctors. Journal of Health, Population, and Nutrition, 25, 205.

[18] Lafta, R.K., Al-shatari, S.A. and Hassan, R.A. (2014) Drug Misuse in the Treatment of Diarrhea among Children under Five Years; a Sample from Baghdad. IRAQI Journal of Community Medicine, 27, 14-17.

[19] Simpson, E., Zwisler, G. and Moodley, M. (2013) Survey of Caregivers in Kenya to Assess Perceptions of Zinc as a Treatment for Diarrhea in Young Children and Adherence to Recommended Treatment Behaviors. Journal of Global Health, 3, Article ID: 010403. https://doi.org/10.7189/jogh.03.010405

[20] Mahapatra, T., Mahapatra, S., Banerjee, B., Mahapatra, U., Samanta, S., Pal, D., Chakraborty, N.D., Manna, B., Sur, D. and Kanungo, S. (2015) Predictors of Rational Management of Diarrhea in an Endemic Setting: Observation from India. PLoS ONE, 10, e0123479. https://doi.org/10.1371/journal.pone.0123479

[21] Kotwani, A., Chaudhury, R.R. and Holloway, K. (2012) Antibiotic-Prescribing Practices of Primary Care Prescribers for Acute Diarrhea in New Delhi, India. Value in Health, 15, S116-S119. https://doi.org/10.1016/j.jval.2011.11.008

[22] Le Grand, A., Hogerzeil, H.V. and Haaijer-Ruskamp, F.M. (1999) Intervention Research in Rational Use of Drugs: A Review. Health Policy and Planning, 14, 89-102. https://doi.org/10.1093/heapol/14.2.89

[23] WHO U (2004) WHO-UNICEF Joint Statement on the Clinical Management of Acute Diarrhea. World Health Assembly, Geneva.

[24] Sharma, L., Gupta, R., Kapadia, R., Gupta, K., Singhal, S., Gupta, J.K., Mathur, M. and Sharma, K. (2015) Auditing of Prescriptions in Relation to Diarrhea in Children below 5 Years of Age: A Multicenter Study. International Journal of Basic \& Clinical Pharmacology, 4, 1208-1213. https://doi.org/10.18203/2319-2003.ijbcp20151360 